\title{
Comparative analysis of lipopolysaccharides of pathogenic and intermediately pathogenic Leptospira species
}

\author{
Kailash P. Patra ${ }^{1 \dagger}$, Biswa Choudhury ${ }^{2 \dagger}$, Michael M. Matthias ${ }^{1}$, Sheyenne Baga ${ }^{1}$, Keya Bandyopadhya ${ }^{2}$
} and Joseph M. Vinetz ${ }^{1 *}$

\begin{abstract}
Background: Lipopolysaccharides (LPS) are complex, amphipathic biomolecules that constitute the major surface component of Gram-negative bacteria. Leptospira, unlike other human-pathogenic spirochetes, produce LPS, which is fundamental to the taxonomy of the genus, involved in host-adaption and also the target of diagnostic antibodies. Despite its significance, little is known of Leptospira LPS composition and carbohydrate structure among different serovars.

Results: LPS from Leptospira interrogans serovar Copenhageni strain L1-130, a pathogenic species, and L. licerasiae serovar Varillal strain VAR 010, an intermediately pathogenic species, were studied. LPS prepared from aqueous and phenol phases were analyzed separately. L. interrogans serovar Copenhageni has additional sugars not found in L. licerasiae serovar Varillal, including fucose (2.7 \%), a high amount of GlcNAc (12.3\%), and two different types of dideoxy HexNAc. SDS-PAGE indicated that L. interrogans serovar Copenhageni LPS had a far higher molecular weight and complexity than that of L. licerasiae serovar Varillal. Chemical composition showed that L. interrogans serovar Copenhageni LPS has an extended O-antigenic polysaccharide consisting of sugars, not present in L. licerasiae serovar Varillal. Arabinose, xylose, mannose, galactose and L-glycero-D-mannoheptose were detected in both the species. Fatty acid analysis by gas chromatography-mass spectrometry (GC-MS) showed the presence of hydroxypalmitate (3-OH-C16:0) only in L. interrogans serovar Copenhageni. Negative staining electron microscopic examination of LPS showed different filamentous morphologies in L. interrogans serovar Copenhageni vs.

L. licerasiae serovar Varillal.
\end{abstract}

Conclusions: This comparative biochemical analysis of pathogenic and intermediately pathogenic Leptospira LPS reveals important carbohydrate and lipid differences that underlie future work in understanding the mechanisms of host-adaptation, pathogenicity and vaccine development in leptospirosis.

Keywords: Lipopolysaccharide, Leptospira, Chemical composition, O-antigen diversity

\section{Background}

Human leptospirosis is a common, globally-important and neglected zoonotic infectious disease, caused by spirochetes of the genus Leptospira [1], a disease of particular public health importance in tropical and subtropical countries [2]. Chronically infected mammalian reservoir

\footnotetext{
* Correspondence: jvinetz@ucsd.edu

${ }^{\dagger}$ Equal contributors

'Division of Infectious Diseases, Department of Medicine, Biomedical Research Facility, University of California San Diego, 9500 Gilman Drive, BRF 2, Room 5220, La Jolla 92093-0760, California, USA

Full list of author information is available at the end of the article
}

hosts (e.g., rodents, cattle, dogs and swine) excrete the organism in urine, contaminating water and soil the principal vehicles for human infection. There are at least 22 recognized species of Leptospira that have been further classified into three major subgroups: Pathogenic, Intermediately Pathogenic and Non-pathogenic (saprophytes) [3], comprising $\geq 250$ serotypes ("serovars") based primarily on the immunological characterization of surface lipopolysaccharide (LPS) [4-6], a feature that distinguishes Leptospira from other human-infecting spirochetes, which do not produce LPS.

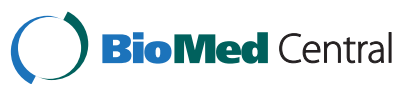

(c) 2015 Patra et al. Open Access This article is distributed under the terms of the Creative Commons Attribution 4.0 International License (http://creativecommons.org/licenses/by/4.0/), which permits unrestricted use, distribution, and reproduction in any medium, provided you give appropriate credit to the original author(s) and the source, provide a link to the Creative Commons license, and indicate if changes were made. The Creative Commons Public Domain Dedication waiver (http://creativecommons.org/publicdomain/zero/1.0/) applies to the data made available in this article, unless otherwise stated. 
LPSs are complex, amphipathic biomolecules that constitute the major surface antigen of Gram-negative bacteria $[7,8]$. LPS is composed of three covalently-linked distinct components: lipid $\mathrm{A}$, which is the hydrophobic part embedded in the outer membrane; $\mathrm{O}$-antigen or $\mathrm{O}$ polysaccharide, which is extended from the cell surface to the external environment; and the core oligosaccharide, which links the O-antigen to the lipid A. LPS with and without $\mathrm{O}$-antigen side chains are referred to as smooth and rough LPS, respectively. Several Gram-negative organisms have been shown to produce heterogeneous (both smooth and rough) LPS $[9,10]$. Leptospira LPS plays an essential role in pathogenesis colonization and dissemination of Leptospira in mouse models [11-13]. LPS is one of the target antigen for diagnosis $[14,15]$ and also potential candidate for vaccine development $[7,16,17]$.

In contrast to the pathogenic strain, L. interrogans serovar Copenhageni strain Fiocruz L1-130, the intermediately pathogenic strain L. licerasiae serovar Varillal strain VAR 010 grows rapidly in vitro, but neither caused disease nor was molecularly detectable in experimentally infected hamsters or mice [18]. L. licerasiae serovar Varillal strain VAR 010 (VAR010) causes mild disease in humans [18] compared to L. interrogans serovar Copenhageni strain Fiocruz L1-130 infection, which frequently result in lifethreatening illness characterized by jaundice, shock, kidney injury and hemorrhage $[19,20]$. These critical observations suggest that there are important biological and virulence differences between pathogenic and intermediately pathogenic Leptospira species, which can be further exploited by comparative analysis of key components to understand the pathogenesis and host colonization. LPS is considered as one of the central component of the pathogenesis in Gram-negative organisms including pathogenic Leptospira species [8, 12]. Therefore, comparative characterization of LPS of a pathogenic and intermediately pathogenic Leptospira species is critical to delineate sugar and fatty acid molecules essential for the pathogenesis and colonization in the host.

Apart from its overall structural similarity to Gramnegative LPS, relatively little is known about the composition and structure of Leptospira LPS [11, 12, 21]. Until now, the chemical composition and structure of the LPS produced by an intermediate Leptospira have not been studied. This is particularly important considering the reduced complexity of the L. licerasiae serovar Varillal rfb locus (a modest 6-gene-operon) compared to that of $L$. interrogans Copenhageni, which contains 91 genes, despite the fact that both serovars have a common reservoir host: Rattus norvegicus [3]. Though this association is not absolute, reservoir species are thought to maintain specific serovars such as Copenhageni in rats and Canicola in dogs. Indeed, despite differing genomic backgrounds, $L$. interrogans subtype Harjoprajitno and L. borgpetersenii serotype Hardjobovis are indistinguishable serologically and share a common reservoir host [22] suggesting that LPS plays an important role in determining hostspecificity.

To establish the biochemical basis for the structural determination of the carbohydrate component of leptospiral LPS, the biochemical composition of LPS of the high-grade pathogenic L. interrogans serovar Copenhageni was compared to the LPS of the intermediately pathogenic L. licerasiae Varillal LPS. Further, of biological relevance given that pathogenic bacterial LPS may well be associated with host adaptation, these two Leptospira share Ratttus species as their mammalian reservoir host [18]. Importantly, the $r f b$ loci of these two Leptospira have great differences in their complexity: L. interrogans serovar Copenhageni has $95 r f b$ locus genes [23], while L. licerasiae has $6 r f b$ locus genes [3]. This study is the first to compare the biochemical composition of LPS from pathogenic and intermediate Leptospira sharing a common reservoir host and having varying pathogenic potentials, and will underpin future structural studies of leptospiral LPS.

\section{Methods}

\section{Ethics statement}

This study was carried out in accordance with the recommendations in the Guide for the Care and Use of Laboratory Animals of the National Institutes of Health in AAALAC-approved facilities. The experimental animal work was approved by the Institutional Animal Care and Use Committee of the University of California San Diego under protocol S03128H.

\section{Strains and culture condition and LPS extraction}

Leptospira interrogans serovar Copenhageni strain Fiocruz L1-130, a pathogen, was maintained in-vitro, passaged through hamsters, and re-isolated from infected hamster liver; low-passage derivatives (P10 or less) were used for all the experiments. The intermediate pathogen, L. licerasiae serovar Varillal (VAR010) was originally isolated from Rattus spp. in the Peruvian Amazon [18], adapted to invitro culture conditions in our laboratory, and analyzed at the whole genome level [3]. Both strains were cultivated in Ellinghausen-McCullough-Johnson-Harris (EMJH) medium (Becton Dickinson, Sparks, Maryland) with slow rotary shaking $(100 \mathrm{rpm})$ at $30^{\circ} \mathrm{C}$. Leptospira cells were collected from mid-log cultures by centrifugation at 14,000 rpm for 30 minutes, and then washed three times with sterile PBS before LPS extraction.

Crude LPS was prepared by hot phenol-water extraction as described previously [24], and extensively dialyzed against Milli-Q water (8 changes for 4 days) to remove phenol then lyophilized. Lyophilized crude material was re-suspended in $10 \mathrm{~mL}$ of Mill-Q water, treated with 
DNase and RNase (Benzonase Nuclease, Sigma-Aldrich, St. Louis, MO) followed by proteinase-K digestion (Sigma-Aldrich, Product No. P6556). Purified LPS was pelleted by ultracentrifugation $\left(120,000 \mathrm{~g}\right.$ for $4 \mathrm{~h}$ at $\left.4{ }^{\circ} \mathrm{C}\right)$, dissolved in Milli-Q water and lyophilized. Stock solutions of $1 \mathrm{mg} / \mathrm{mL}$ of purified LPS were prepared from both aqueous and phenol phases, and known amounts (by weight) were used for SDS-PAGE and chemical composition analysis.

\section{Chemical composition analysis of LPS extracted from aqueous ( $\mathrm{AQ}$ ) and phenol $(\mathrm{PH})$ phases}

Neutral monosaccharides were identified by GC-MS as their alditol acetate derivative (AA). Briefly, a known amount of LPS was spiked with $2 \mu \mathrm{g}$ of myo-inositol as internal standard, followed by hydrolysis with $2 \mathrm{~N}$ trifluoroacetic acid (TFA) at $100{ }^{\circ} \mathrm{C}$ for $4 \mathrm{~h}$. Hydrolyzed samples were cooled to room temperature, and a dry nitrogen flush used to remove excess acid followed by repeated coevaporation of the reaction mixture with $100 \mu \mathrm{l}$ of $50 \%$ aqueous isopropyl alcohol. The liberated monosaccharide aldoses were further reduced to corresponding alditols by sodium borohydride solution $(1 \mathrm{mg} / \mathrm{mL}$ in $1 \mathrm{M}$ ammonium hydroxide) at room temperature overnight. Excess sodium borohydride was neutralized using cold aqueous $30 \%$ acetic acid (HOAc), followed by removal of boric acid from the reaction mixture as volatile methyl borate using a dry nitrogen flush. Finally, sugar alditols were reacted with a 1:1 (v/v) mixture of pyridine and acetic anhydride at $100{ }^{\circ} \mathrm{C}$ for $1 \mathrm{~h}$ to form corresponding alditol acetate derivatives. After removal of excess reagent by dry a nitrogen flush, dried samples were extracted with dichloromethane and analyzed by GC-MS (Agilent Technologies 7820A GC system; 5975 Series MSD) using a Restek-5 ms (Restek Cat No. 13423) capillary column. Ultrapure helium was used as carrier gas at a linear flow rate of $1.25 \mathrm{~mL} / \mathrm{min}$ and a temperature gradient $\left(120{ }^{\circ} \mathrm{C}-10{ }^{\circ} \mathrm{C}\right.$ for $1 \mathrm{~min}, 140{ }^{\circ} \mathrm{C}-2{ }^{\circ} \mathrm{C}$ for $1 \mathrm{~min}, 220{ }^{\circ} \mathrm{C}$ for $2 \mathrm{~min}, 5{ }^{\circ} \mathrm{C}$ for $1 \mathrm{~min}$ and $230{ }^{\circ} \mathrm{C}$ for $4 \mathrm{~min}$ ). The injector temperature and transfer temperatures were maintained at $220{ }^{\circ} \mathrm{C}$ and $280{ }^{\circ} \mathrm{C}$ respectively. The constituent monosaccharides in LPS were identified and quantified by comparing the retention time and mass fragmentation pattern in electron impact (EI) positive ion mode with standard sugars.

Fatty acid analysis of AQ and PH layers by GC-MS as fatty acid methyl ester (FAME) and trimethyl silyl ether (Tri-Sil)FAME of hydroxyl fatty acids

Dried LPS samples $(50 \mu \mathrm{g})$ from both aqueous and phenol layers were treated with $200 \mu \mathrm{L} 1 \mathrm{M}$ methanolic $\mathrm{HCl}$ prepared using a $3 \mathrm{~N}$ methanolic $\mathrm{HCl}$ kit (Supelco, Cat No. 3-3355) for $16 \mathrm{~h}$ at $80{ }^{\circ} \mathrm{C}$. The samples were placed in an ice bath and slowly evaporated under a dry nitrogen stream until almost half of the sample volume had evaporated. To this reaction mixture, cold halfsaturated $\mathrm{NaCl}$ was added followed by the addition of $1 \mathrm{~mL}$ chloroform. The samples were vortexed at high speed for $1 \mathrm{~min}$ with a 20 -sec pulse, and then allowed to settle for $1 \mathrm{~min}$, and then centrifuged at $2000 \mathrm{rpm}$ for 2 min (Beckman Coulter, Allegra 25R centrifuge) to separate organic and aqueous layers. The lower organic layer was carefully removed to a glass hydrolyzing tube, and the aqueous layer was extracted twice with $0.5 \mathrm{~mL}$ of chloroform. Chloroform fractions were pooled then washed with $2.0 \mathrm{~mL}$ of cold Milli-Q water twice, and the organic layer was dried down. For detection of hydroxy fatty acids, the dried fatty acid methyl esters were treated with $100 \mu \mathrm{L}$ of Tri-Sil HTP reagent (Thermo Scientific, Cat No. TS-48999) at $80{ }^{\circ} \mathrm{C}$ for $30 \mathrm{~min}$. The samples were cooled in an ice bath and then dried using a dry nitrogen stream, and then dissolved in hexane and analyzed by GC-MS.

FAME derivatized samples were analyzed by GC-MS (Agilent Technologies 7820A GC system; 5975 Series MSD) using a Restek-5 ms (Restek Cat No. 13423) capillary column. Ultrapure helium was used as a carrier gas at a linear flow rate of $1.1971 \mathrm{~mL} / \mathrm{min}$ and the following temperature gradient $\left(100{ }^{\circ} \mathrm{C}-5{ }^{\circ} \mathrm{C}\right.$ for $1 \mathrm{~min}$, $120{ }^{\circ} \mathrm{C}$ for $1 \mathrm{~min}, 3{ }^{\circ} \mathrm{C}$ for $1 \mathrm{~min}$ and $-230{ }^{\circ} \mathrm{C}$ for $4 \mathrm{~min})$. The injector temperature and transfer line temperature were maintained at $220{ }^{\circ} \mathrm{C}$ and $280{ }^{\circ} \mathrm{C}$. Fatty acids were identified by their characteristic EI fragmentation pattern and corresponding retention times and the percentage composition calculated from the area under the respective peaks.

\section{KDO (2-keto-3-deoxyoctonate) analysis}

KDO was analyzed using reverse phase HPLC with a C18 column after tagging with a fluorophore 4, 5 methylenedioxy-1, 2-phenylenediamine dihydrochloride (DMB) (Sigma, A89804). Briefly, $25 \mu \mathrm{g}$ of LPS was hydrolyzed using $100 \mu \mathrm{L}$ of $2 \mathrm{M} \mathrm{HOAc}$ at $80{ }^{\circ} \mathrm{C}$ for $3 \mathrm{~h}$ followed by removal of HOAc in a speed vac. The sample was then spin filtered using a $10 \mathrm{~K}$ (MW cut off) spin filter (Nanosep $10 \mathrm{~K}$ Omega, PALL Life Sciences, product No. OD010C34). The flow-through containing free $\mathrm{KDO}$ was reacted with $\mathrm{DMB}$ reagent at $50{ }^{\circ} \mathrm{C}$ for $2.5 \mathrm{~h}$; a known amount of DMB-KDO was injected into an RP-HPLC equipped with an online fluorescence detector (Dionex Ultimate 3000 UHPLC-Focused Plus). A Phenomenex C18 reverse phase column $(250 \mathrm{~mm} \times 4.6 \mathrm{~mm}$, 5 micron particle size) was used for HPLC analysis with an isocratic solvent mixture of consisting of methanol (8\%) and acetonitrile (5\%). For fluorescence detection, the excitation and emission wavelengths were set to $373 \mathrm{~nm}$ and $448 \mathrm{~nm}$ respectively. 


\section{Electron microscopy}

A drop of LPS solution $(1 \mathrm{mg} / \mathrm{mL}$ in water) was deposited on a carbon coated mesh grid (200 lines/inch) and airdried. The sample containing mesh was negatively stained with $2 \%(\mathrm{w} / \mathrm{v})$ uranyl acetate following a published method [18]. The air-dried stained grid was examined using a Joel 1200 Ex II TEM microscope at $80 \mathrm{kV}$ available at the core facility at UC San Diego (emcore.ucsd.edu).

\section{Results}

\section{Electrophoretic mobilty of LPS extracted from $A Q$ and PH} phases

The silver-stained electrophoretic profiles of LPS fractions from L1-130 and VAR 10 were compared with that of an E. coli control (Fig. 1). The migration pattern of Leptospira LPS of both strains did not show the ladder-like pattern, characteristic Gram-negative smooth (S) LPS. The electrophoretic mobility of VAR010 LPS found in AQ and PH layers were similar, consisting of fast migrating low-MW band. By contrast, the AQ and PH layers of L1-130 LPS were distinct. L1-130 LPS isolated from the AQ layer displayed higher-MW to low-MW bands, forming a smear like pattern.

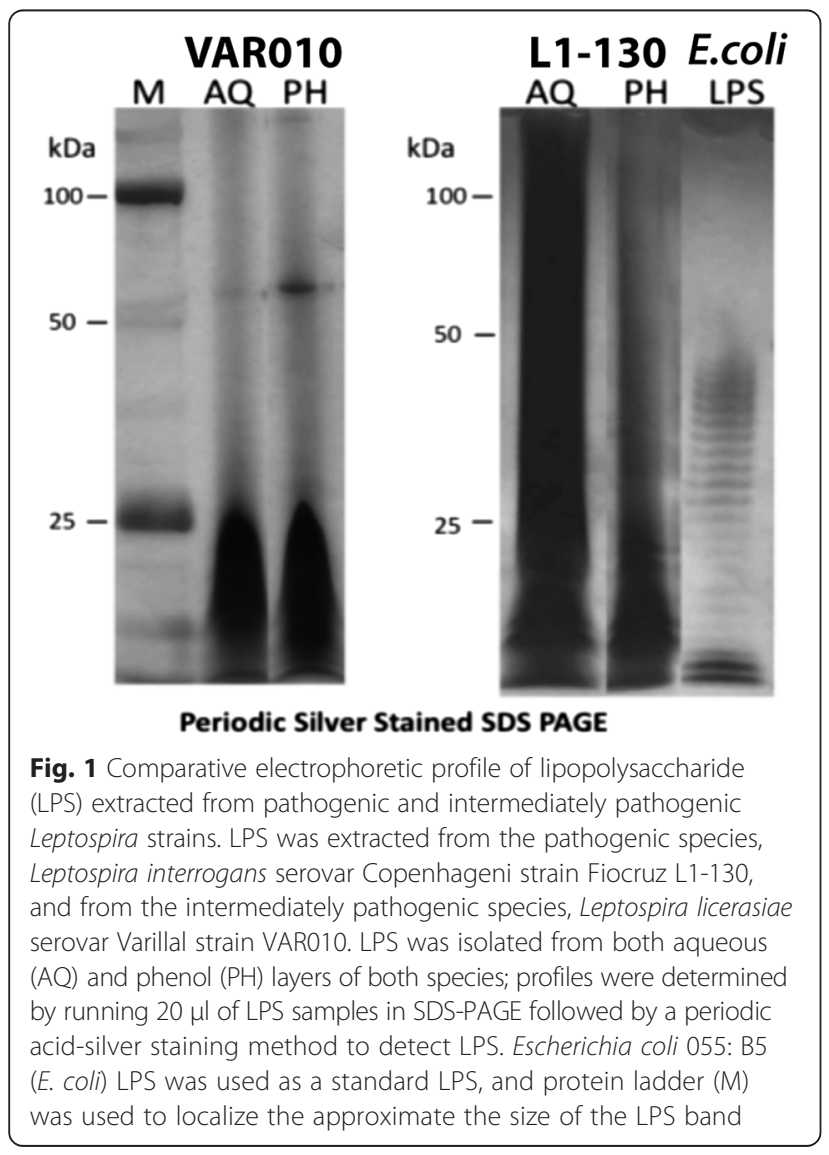

\section{GC-MS analysis of monosaccharides obtained from AQ and PH phase LPS}

The carbohydrate composition of LPS of serovars Copenhageni and Varillal are summarized in Fig. 2 and Table 1. The monosaccharides present in both the strains are arabinose (Ara), rhamnose (Rha), xylose (Xyl), mannose (Man) and galactose (Gal). Several other sugar moieties are only present in the pathogen $L$. interrogans Copenhageni were detected, including fucose (Fuc, $2.7 \%$ ), Nacetylglucosamine (GlcNAc, $12.3 \%$ in Aq-LPS and $2.03 \%$ in Ph-LPS) and trace amounts of $\mathrm{N}$-acetylgalactosamine (GalNAc, $0.35 \%$ in the AQ layer). Two other sugars were present only in the AQ layer of serovar Copenhageni (Fig. 2), epimers of 2-N-acetyl-2, 6-dideoxy hexosamine (2,6-dideoxyHexNAc). The retention time suggests these sugars could be either gluco- or galacto- configured dideoxy HexNAc sugars, commonly known as $\mathrm{N}$-acetyl quinovosamine (QuiNAc) and N-acetyl fucosamine (FucNAc). Chemical composition analysis also demonstrated the presence of $\mathrm{O}$-methylated hexose residue in different fractions of LPS of both strains.

\section{Fatty acid composition analysis of LPS from intermediate} and pathogenic strain

The fatty acid composition of different LPS fractions from L. interrogans serovar Copenhageni strain Fiocruz L1-130 and L. licerasiae serovar Varillal strain VAR010 (VAR010) are summarized in Table 2 and their corresponding GCMS spectra are shown in Fig. 3. The LPSs consist of hydroxyl-lauric acid (3-OH C12:0); palmitic acid (C16:0); stearic acid (C18:0); oleic acid (C18: 1); myristic (C14:0) acid; hydroxyl-myristic acid (3-OH C14:0), hydroxyl palmitic acid (3-OH C16:0), and several other minor fatty acids such as myristoleic acid (C14: 1) and palmitoleic acid (C16: 1). Hydroxylauric (3-OH-C12:0) was present in higher amounts in serovar Copenhageni LPS as compared to that of Varillal, and hydroxypalmitate was only detected in serovar Copenhageni.

\section{Analysis of KDO}

$\mathrm{KDO}$ in $\mathrm{AQ}$ and $\mathrm{PH}$ layer of $L$. interrogans serovar Copenhageni strain Fiocruz L1-130 was estimated to be 3.6 and 4.7 pmole per $12.5 \mu \mathrm{g}$ of LPS, respectively (Fig. 4a, b). The KDO contents were strikingly low in $L$. licerasiae serovar Varillal strain VAR010 in both phenol and aqueous layer LPS samples (Fig. 4c and d).

\section{Ultra-structure of Leptospiral LPS}

Electron microscopic examination of negatively stained LPS extracted from $L$. interrogans serovar Copenhageni strain Fiocruz L1-130 and L. licerasiae serovar Varillal strain VAR010 had different morphologies (Fig. 5). VAR010 LPS is a closely packed sheet comprised of interwoven smaller thread-like filaments (Fig. 5a). By contrast, 

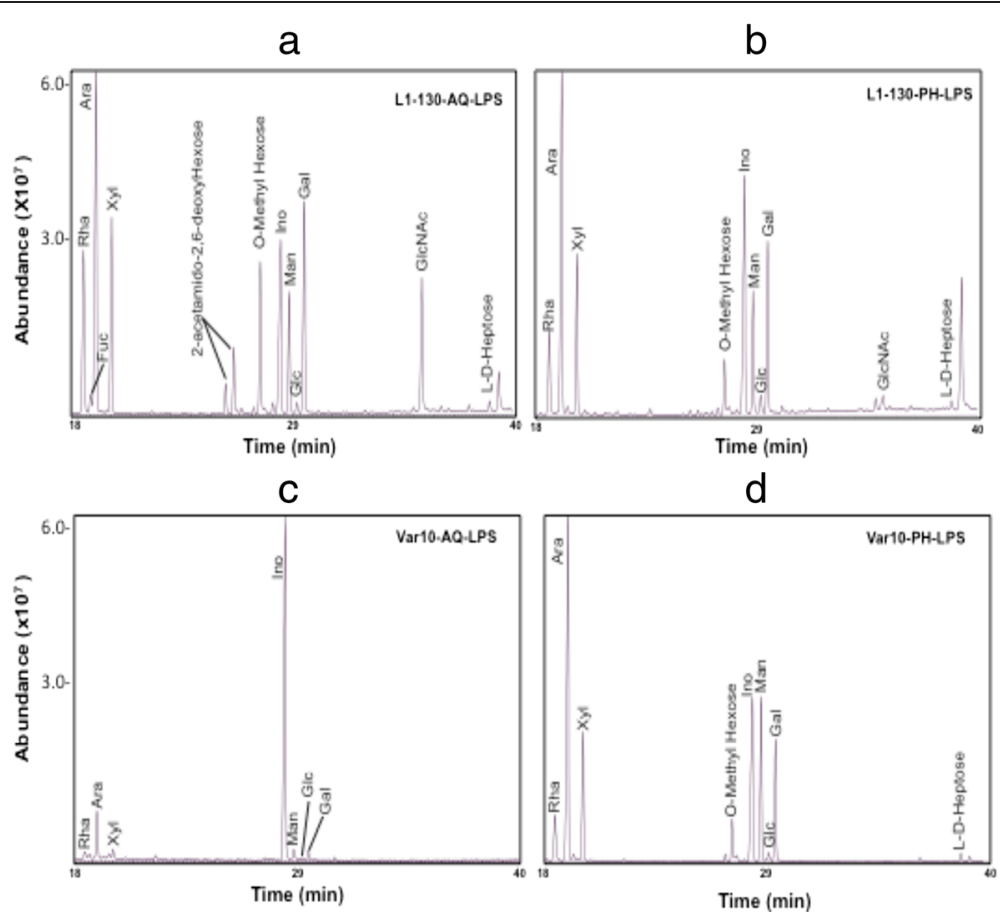

Fig. 2 Carbohydrate composition analysis of LPS of pathogenic and intermediate pathogenic Leptospira strains. LPS extracted from the pathogenic species, Leptospira interrogans serovar Copenhageni strain Fiocruz L1-130, and from the intermediately pathogenic species, Leptospira licerasiae serovar Varillal strain VAR010, was subjected to gas chromatography-mass spectrometry (GC-MS) chromatography of monosaccharides as alditol acetate derivatives: (a) Copenhageni aqueous layer LPS; (b) Copenhageni phenol layer LPS; (c) VAR010 aqueous layer LPS; (d) VAR010 phenol layer LPS. Rha =6-deoxymannopyranose; Fuc =6-deoxygalactopyranose; Ara = arabinose; Xyl =xylose; Ino = Myo-inositol (internal standard); Man = mannose; Glc = glucose; Gal = galactose; GlcNAc = 2-N-acetylglucosamine; L-D-Heptose = L-glycero-D-mannoheptose

L1-130 LPS consisted of filaments are larger in size, clustered together that did not form any definite sheet like structure (Fig. 5b).

\section{Discussion}

Here we report key experimentally-determined biochemical details of the composition of the lipopolysaccharide (LPS) of L. licerasiae serovar Varillal, an intermediate pathogen leptospire with unique antigenicity [18], broad reactivity among people resident in the Peruvian Amazon [18], and an unusually small $r f b$ locus comprised of only 6 genes [3]. This analysis of $L$. licerasiae serovar Varillal LPS demonstrated important differences when compared to the LPS of the highly pathogenic L. interrogans serovar Copenhageni. We found that $L$. licerasiae Varillal and $L$. interrogans Copenhageni LPS differ significantly in carbohydrate and fatty-acid compositions, particularly in that $L$. interrogans serovar Copenhageni was found to contain fucose, $\mathrm{N}$-acetylglucosamine and $\mathrm{N}$-acetylgalactosamine, FucNAc and QuicNAc and hydroxypalmitate (3-OHC16:0) while L. licerasiae serovar Varillal did not.

While leptospiral LPS does not have potent endotoxigenic properties [25], it has long been known to be the antigen that defines serovar and serogroups, and anti- leptospiral LPS antibodies are responsible for serovarspecific immunity [26-36]. Leptospira LPS plays a major role in immunity $[37,38]$, potential candidate for vaccine development [17] and also anti-LPS monoclonal antibodies used for diagnosis [14, 17]. In contrast, the other human-infecting spirochetes-Borrelia spp. and Treponema spp.- do not have LPS or an outer membrane [12], so that these biochemical components and structures do not play a role in the biology of these pathogens. Transposon mutants, deficient in LPS production, demonstrated that LPS is a critical virulence determinant and is necessary for colonization of the vertebrate host [12, 37], similar to that of Salmonella spp. LPS [39]. However, detailed analysis of leptospiral LPS remains understudied, and the present report provides a new approach to such studies.

In our observations, purification of LPS from Leptospira species differed from other Gram-negative organisms, in which LPS precipitation primarily occurs from the aqueous phase of hot phenol-water extracts. In earlier studies, aqueous phase Leptospira LPS were used for composition analysis, immunological and biological studies [18, 26-28]. However, a substantial amount of Leptospira LPS also separates into the phenol layer 
Table 1 Cabohydrate composition analysis of LPS of pathogenic versus intermediate pathogenic Leptospira strains

\begin{tabular}{|c|c|c|c|c|c|c|}
\hline \multirow[t]{2}{*}{ Sugar } & \multicolumn{3}{|c|}{ Pathogenic L1-130 } & \multicolumn{3}{|c|}{ Intermediate pathogenic VAR010 } \\
\hline & AQ LPS & PH LPS & Ave (SD) & AQ LPS & PH LPS & Ave (SD) \\
\hline Arabinose (Ara) & 20.45 & 20.56 & $20.5(0.05)$ & 39.32 & 33.52 & $36.4(5.8)$ \\
\hline Rhamnose (Rha) & 20.56 & 15.03 & $17.8(2.8)$ & 16.08 & 10.84 & $13.5(2.6)$ \\
\hline Fucose (Fuc) & 2.17 & $0(\mathrm{ND})$ & $1.1(1.1)$ & $0(N D)$ & $0(N D)$ & 0 (ND) \\
\hline Xylose (Xyl) & 19.88 & 23.27 & $21.8(1.7)$ & 18.99 & 21.06 & $20.0(1.0)$ \\
\hline Mannose (Man) & 8.74 & 12.73 & $10.7(2.0)$ & 15.56 & 19.91 & $17.7(2.2)$ \\
\hline Galactose (Gal) & 14.66 & 16.65 & $15.7(1.0)$ & 7.87 & 13.2 & $10.5(2.7)$ \\
\hline Glucose (Glc) & 0.89 & 2.29 & $1.59(0.7)$ & 2.18 & 1.48 & $1.6(0.7)$ \\
\hline N-acetylglucos- amine (GlcNAc) & 12.3 & 2.03 & $7.2(5.1)$ & $0(N D)$ & $0(N D)$ & $0(\mathrm{ND})$ \\
\hline N-acetylgalacto-samine (GalNAc) & 0.35 & $0(\mathrm{ND})$ & $0.18(0.18)$ & $0(N D)$ & $0(N D)$ & $0(\mathrm{ND})$ \\
\hline 2-N-acetyl-2,6-dideoxy galactose (FucNAc) & $+(*)$ & $0(\mathrm{ND})$ & $+\left({ }^{*}\right)$ & $0(N D)$ & $0(N D)$ & $0(\mathrm{ND})$ \\
\hline 2-N-acetyl-2,6-dideoxy Glucose (QuiNAc) & $+(*)$ & $0(\mathrm{ND})$ & $+\left({ }^{*}\right)$ & $0(N D)$ & $0(N D)$ & $0(\mathrm{ND})$ \\
\hline L-glycero-D-manno Heptose (L-D-Hep) & 3.0 & 4.31 & $3.65(0.7)$ & $0(N D)$ & 4.03 & $2.0(2.0)$ \\
\hline
\end{tabular}

LPS from Leptospira interogans serovar Copenhageni strain L1-130 (L1-130) and intermediate pathogenic, Leptospira licerasiae serovar Varillal strain VAR010 (VAR010) were purified from both aqueous ( $\mathrm{AQ}$ ) and phenol layer $(\mathrm{PH})$ and subjected for composition analysis separately. The sugar composition values of aqueous, phenol and combined mean values $( \pm \mathrm{SE}$ ) are presented as mole percentage of monosaccharides obtained in fractions. ND= not detected; FucNAc $=2$-Nacetyl-2, 6-dideoxy Galactose and QuiNAc = 2-Nacetyl-2, 6-dideoxy Glucose (*). FucNAc and QicNAc are proposed according to the El mass fragmentation pattern and relative retention times; however quantification could not be done due to unavailability of authentic standards for both monosaccharides

during LPS extraction procedures like Gram-negative bacteria that contain smooth LPS [9]. Our results indicate that Leptospira LPS is distributed differently in phenol and aqueous layer in pathogenic (L1-130) and intermediate pathogenic strain (VAR010). The distribution of LPS in organic and aqueous layers mainly depends on the ratio of hydrophilic saccharide portion and hydrophobic lipid part of the LPS [40, 41]. We analyzed LPS isolated from both aqueous and phenol layers separately to compare chemical composition of serovars Copenhageni and Varillal. The growth temperature of an organism may also influence the LPS composition and solubility. For example, in Yersinia pestis the LPS compositions changes under two different growth conditions (mammalian, $37^{\circ} \mathrm{C}$ and environmental $25^{\circ}$ C) mimicking host body temperatures [42] and similarly evident in other pathogens [43, 44]. O-antigen content of $L$. interrogans has been observed to change between acute and chronic infection, and when cultivated under in vitro conditions [13]. Interestingly, transmission of leptospirosis requires that Leptospira survive and adapt to a wide variety of conditions (renal tubules, urine, river, mud, soil, etc.) and characteristics of these adaptations are not clear [13]. We cultured both Leptospira species (L1-130 and VAR010) at $30{ }^{\circ} \mathrm{C}$ in a medium rich in long chain fatty acids (EMJH medium), a standard method. A potential and important limitation of the present study is that only the LPS

Table 2 Percentage of fatty acid composition analysis of LPS of pathogenic versus intermediate pathogenic Leptospira strains

\begin{tabular}{|c|c|c|c|c|c|c|}
\hline \multirow[t]{2}{*}{ Fatty acid } & \multicolumn{3}{|c|}{ Pathogenic L1-130 } & \multicolumn{3}{|c|}{ Intermediate pathogenic VAR010 } \\
\hline & AQ LPS & PH LPS & Ave $( \pm$ SD) & AQ LPS & PH LPS & Ave $( \pm S D)$ \\
\hline Myristoleic $\left(C_{14: 1}\right)$ & 0.0 & 1.32 & $0.66(1.98)$ & 0.71 & 1.37 & $1.04(0.33)$ \\
\hline Myristic acid $\left(\mathrm{C}_{14: 0}\right)$ & 0.19 & 0.60 & $0.395(0.205)$ & 0.11 & 0.38 & $0.245(0.135)$ \\
\hline Hydroxylauric $\left(3-\mathrm{OH}-\mathrm{C}_{12: 0}\right)$ & 40.02 & 36.12 & $38.07(1.95)$ & 8.24 & 11.88 & $10.06(1.82)$ \\
\hline Palmitoleic $\left(C_{16: 1}\right)$ & 2.32 & 3.45 & $2.89(0.565)$ & 0.0 & 1.48 & $0.74(0.74)$ \\
\hline Palmitic $\left(C_{16: 0}\right)$ & 28.67 & 24.39 & $26.53(2.14)$ & 71.34 & 51.80 & $61.57(9.77)$ \\
\hline 3-Hydroxymyristate $\left(3-\mathrm{OH}-\mathrm{C}_{14: 0}\right)$ & 0.97 & 0.94 & $0.955(0.015)$ & 3.55 & 4.28 & $3.915(0.365)$ \\
\hline Margaric acid $\left(\mathrm{C}_{17: 0}\right)$ & 0.0 & 0.46 & $0.23(0.23)$ & 0 & 0.24 & $0.12(0.12)$ \\
\hline Oleic $\left(C_{18: 1}\right)$ & 11.78 & 19.19 & $15.49(3.705)$ & 1.37 & 16.27 & $8.82(7.45)$ \\
\hline Steric $\left(C_{18: 0}\right)$ & 2.57 & 2.40 & $2.49(0.085)$ & 14.47 & 12.28 & $13.375(1.095)$ \\
\hline 3-hydroxypalmitate $\left(3-\mathrm{OH}-\mathrm{C}_{16: 0}\right)$ & 13.48 & 11.14 & $12.31(1.17)$ & 0.0 & 0.0 & 0.0 \\
\hline
\end{tabular}

LPS from Leptospira interogans serovar Copenhageni strain L1-130 (L1-130) and intermediate pathogenic, Leptospira licerasiae serovar Varillal strain VAR010 (VAR010) were purified from both aqueous (AQ) and phenol layer $(P H)$ and subjected for composition analysis separately. Fatty acids in both aqueous (AQ) and phenol (PH) layer LPS extracts were measured and given in the table. Average (Ave) and Standard deviation ( \pm SD) values are also presented in this table 


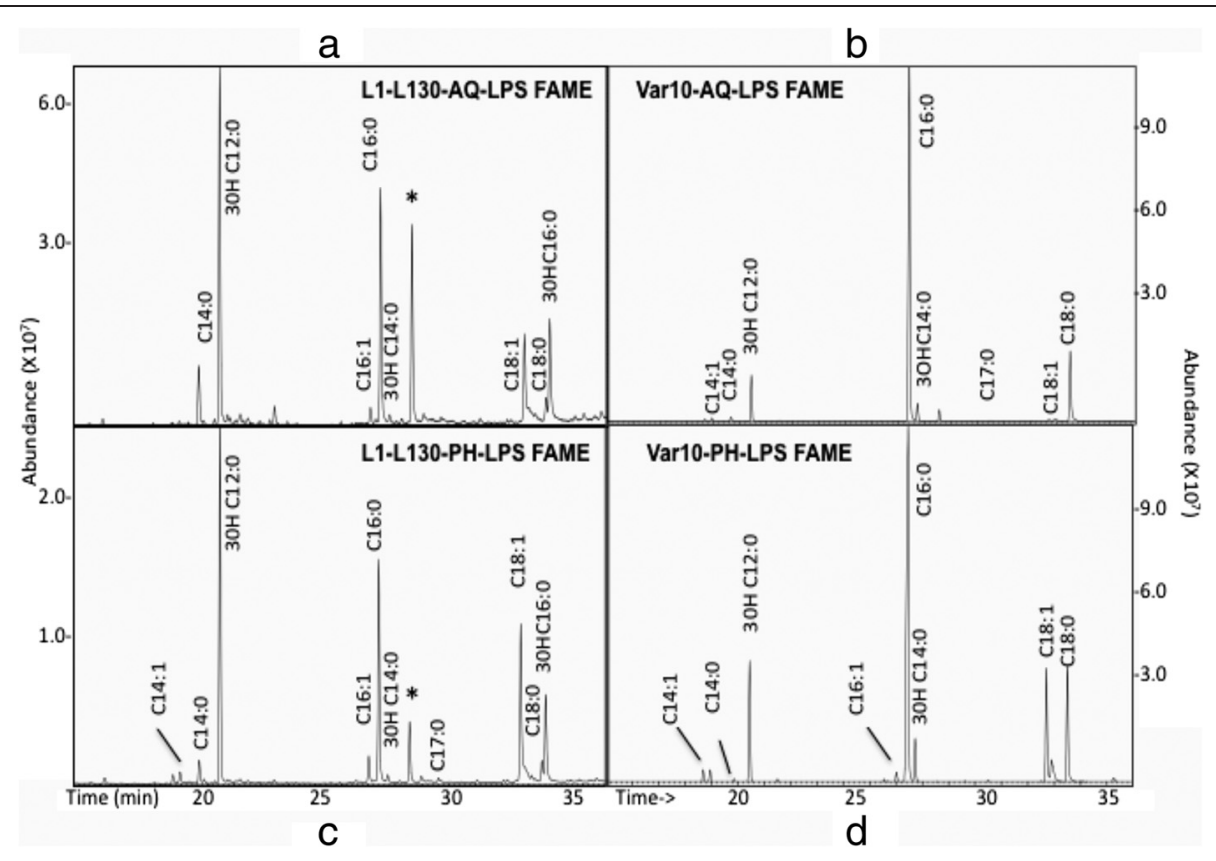

Fig. 3 Fatty acid composition analysis of lipopolysaccharide (LPS) from pathogenic and intermediately pathogenic Leptospira species. LPS was extracted from the pathogenic species Leptospira interrogans serovar Copenhageni strain Fiocruz L1-130 and the intermediately pathogenic species Leptospira licerasiae serovar Varillal strain VAR010. LPS fractions were analyzed by gas chromatography-mass spectrometry (GC-MS) as fatty acid methyl ester (FAME) and trimethyl silyl ether-FAME derivatives of hydroxyl fatty acids: (a) Copenhageni aqueous layer LPS; (b) VAR010 aqueous layer LPS; (c) Copenhageni phenol layer LPS; (d) VAR010 phenol layer LPS

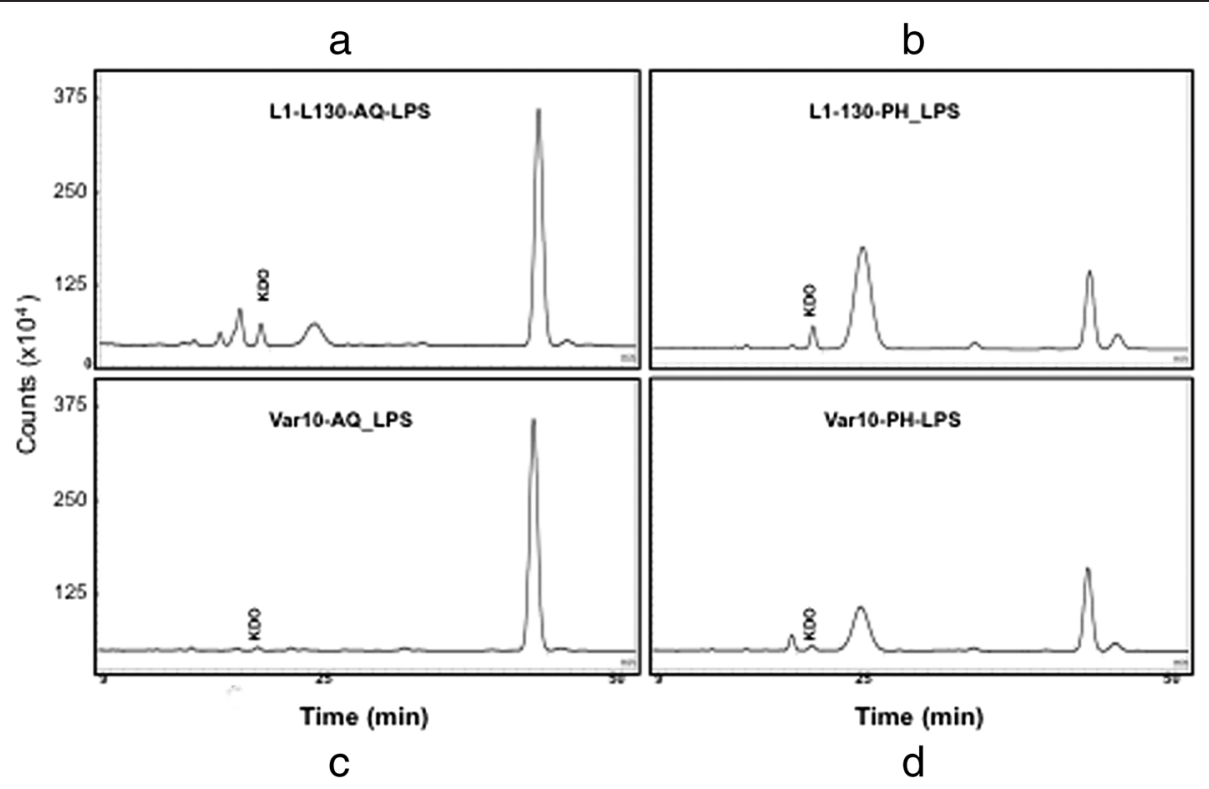

Fig. 4 Detection and quantitative estimation of 2-keto-3-deoxyoctonate (KDO) in pathogenic and intermediately pathogenic Leptospira species. LPS extracted from the pathogenic species Leptospira interrogans serovar Copenhageni strain Fiocruz L1-130, and the intermediately pathogenic species Leptospira licerasiae serovar Varillal strain VAR010 was subjected to KDO analysis using reverse phase HPLC with a C18 column after tagging with a fluorophore 4, 5 methylenedioxy-1, 2-phenylenediamine dihydrochloride (DMB). a Copenhageni aqueous layer LPS; (b) VAR010 aqueous layer LPS; (c) Copenhageni phenol layer LPS; (d) VAR010 phenol layer LPS 

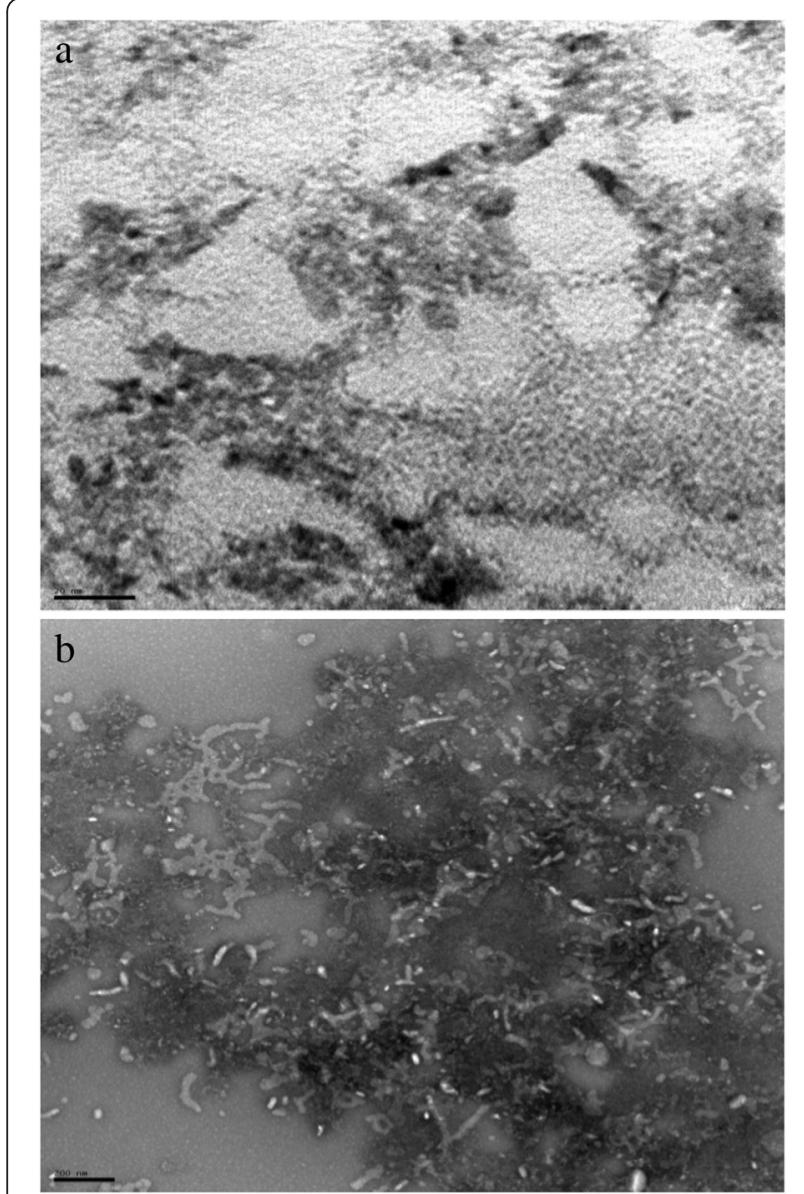

Fig. 5 Electron micrograph of lipopolysaccharide extracted from pathogenic and intermediate pathogenic Leptospira strains. LPS were spotted on a carbon-coated mesh, air-dried, negatively stained with $2 \%$ uranyl acetate and examined under a transmission electron microscope. The pictures show the different LPS structures of intermediately pathogenic (L. licerasiae serovar Varillal strain VAR010, top figure a scale bar $0.5 \mu \mathrm{M}$.) and pathogenic (L interogans serovar Copenhageni strain Fiocruz L-130, bottom figure $\mathbf{b}$ scale bar 0.2) strains, respectively

of in vitro cultivated bacteria were studied. We obtained sufficient amount of LPS from the in-vitro cultured Leptospira strains (L1-130 and VAR010) for chemical analysis, which is currently not feasible from in vivo growing Leptospira.

Analysis of LPS by SDS-PAGE followed by periodic acid-silver staining has been used to characterize LPS heterogeneity in different Leptospira serovars [27] and other Gram-negative bacteria [9, 33, 34]. The periodicsilver stain gel (Fig. 1) shows that in the L1-130, the fastest migrating LPS component is probably the lipidA core, and the slower migrating components are Oantigens as seen in other Gram-negative organisms. In VAR010 LPS are very compact (ranges up to $25 \mathrm{kDa}$ ) in both aqueous/phenol layers LPS extraction. E. coli LPS is characterized by a close succession of regularly spaced bands representing increasing number of $\mathrm{O}$ antigen units. However, in L1-130 the O-side chain patterns may be irregular resulting in a smear-like pattern. The results make evident that the intermediate strain appears to possess the rough type of LPS compared to pathogenic strain that has both smooth and rough form, and further suggests that the O-antigen carbohydrates in Leptospira are not simple repeating units. This finding is particularly important as the $\mathrm{O}$-antigen changes have been previously observed in the same pathogenic strain in acute versus chronic $L$. interrogans infection animal model [13] and serial passaging in immunoincompetent hosts in other organisms [36]. Because of the current lack of a small animal model for L. licerasiae (or other intermediately pathogenic Leptospira), the VAR010 strain was maintained by in-vitro culture, which possibly could have led to some sort of change in LPS molecule. However, anti-VAR010 antisera continue to agglutinate the in vitro passaged strain suggesting that the essential antigen determinants are preserved. Our recent data showed that we could infect Rattus norvegicus with VAR010 to infect and establish chronic renal infection (unpublished data, Carla Fernandez, Michael M. Matthias and Joseph M. Vinetz, 2015).

We demonstrated that the sugar composition of LPS of L1-130 and VAR010 differs, and that the LPS purified from aqueous and phenol layers of these Leptospira is different. Interestingly, fucose, $\mathrm{N}$-acetylglucosamine and N-acetylgalactosamine are only found in L1-130 and not detected in the VAR010 LPS samples. FucNAc and QuicNAc are only found in the aqueous layer LPS from L1-130, and both the sugars are reported to be present on the $\mathrm{O}$-antigen repeat unit of semi-rough or smooth type LPS in different pathogenic bacterial species such as Vibrio cholera and Pseudomonas $[45,46]$. Earlier publications show that there are high content of rhamnose and arabinose in the LPS of pathogenic Leptospira species, L. interrogans serovar Copenhageni and L.interrogans serovar Hardjo [21, 47]. However, we observed in the intermediate-pathogenic Leptospira species, VAR010, arabinose amount was two-fold higher compared to rhamnose. Therefore, we hypothesize that arabinose could play a protective role in survival under certain environmental conditions. Azospirillums showed that a high arabinose content in exopolysaccharide (EPS) plays an important role in cell aggregation that allows survival in a hostile environment $[48,49]$.

In Gram-negative organisms lipid A is responsible for the endotixic activity [8]. The lipid A of L. interrogans has been reported to be structurally different from other enterobacterial lipid A [25], and to be recognized by the mouse innate immune system by TLR- 2 and not TLR- 4 [50]. The lipid A center is an essential component for the viability of most bacteria, with a few exceptions. For 
example, Neisseria meningitidis can survive without lipid $A$ in the presence of capsular polysaccharide [51, 52]. The biological activity of LPS is dependent on several structural features of the lipid A. Among them, the presence of phosphate group, substitution of the phosphate residues (with phosphoethanolamine, phosphocholine and methyl groups), alteration of fatty acyl residues, fatty acid type and chain length [53].

The fatty acid moieties present in the lipid A consist of chain lengths between C10-C14 in majority of organisms and few organisms show C16-C18 [8]. For examples, $P$. aeruginosa expresses fatty acid of shorter chain length $\mathrm{C} 10$ and $\mathrm{C} 12 ; \mathrm{H}$. pylori possess longer chain of fatty acids (C16-C18) and $H$. influenzae present $\mathrm{C} 14$ fatty acids [54]. In Enterobacteriaceae LPS, 3-OH-C14:0 is the dominant 3-OH-fatty acids [55]. The LPS of E. coli contains fatty acids with chain length of $\mathrm{C} 12$ and $3-\mathrm{OH}$ C14:0 [8]. We analyzed the fatty acid from E. coli 011:B4 (Sigma, \# L 2630, Data not shown here) indicated the presence of 3-OH C14:0 as the major component. The LPS of VAR010 shows the presence of $3-\mathrm{OH}$ C14:0, however it's percentage is lot less in pathogenic strains. Interestingly, 3-OH fatty acids $\mathrm{C} 16: 0$ is only present in L1-130 and not detected in VAR010. In Gram-negative organisms, 3-Hydroxy long-chain fatty acids are essential to the endotoxin activity and also used as a chemical markers of LPS [56], hence the role of 3-OH C16:0 in L1-130 need further evaluations. Hydroxylauric acid present in both VAR010 and L1-130 in different ratio, these finding was reported previously for L1-130 [25]. The fatty acid composition differed between the pathogenic (L1-130) and intermediate pathogenic Leptospira (VAR010) that we studied here; for example, fatty acid hydroxypalmitate (3-OH-C16:0) was unique to the pathogenic strain. The Leptospira have a unique metabolism that requires a fatty acid-enriched medium $[57,58]$, and in the host infectious Leptospira colonize kidney as a key component of their life cycle [59]. These organs offer a large amount of lipid supply to meet the essential fatty acids requirements for spirochetes growth and multiplication [60]. The fatty acid metabolic pathway of unique fatty acids of pathogenic Leptospira LPS can be a good target for the intervention to prevent disease progression. Fatty acid composition has previously been suggested to be related to pathogenicity, and this feature merits for further investigation [61].

We carried out extensive processing to remove the nucleic acids and protein contaminant from the LPS preparation by nucleases treatment, proteolytic digestion, ultracentrifugation and dialysis as per published method of Leptospira LPS purification [24]. However, it is possible that glycoproteins that are tightly complexed with LPS and not amenable to protease digestion may contribute to the lipid content. We acknowledge this as a potential limitation of the LPS preparation by available method. The percentages of fatty acids commonly found in both strains such as palmitic acid, stearic and oleic acid are contributions from some non-LPS components such as glycolipoproteins that are co-extracted with the LPS and could not be removed.

KDO (2-keto-3-deoxymanno-octulosonic acid) is an eight carbon acidic sugar found in the LPS of Gramnegative bacteria and it connects the Lipid A part to the $\mathrm{O}$-antigen. The conflicting ability to detect KDO and detection of KDO in some pathogenic strains [11, 18, 26] [24] makes it interesting to understand how sugars might play a substitute role in the absence or limited amount of KDO. We also found KDO in the phenol phase extract of both virulent and intermediate strain and the aqueous phase of the virulent strain only. The amount of KDO in the intermediate was very low with a small peak eluted at the same retention time corresponding to standard KDO and L1-130 KDO peak. It is possible that in the intermediately pathogenic strain other sugars or other form of KDO might also be playing a role in maintaining the weak linkage between $\mathrm{O}$ antigenic carbohydrate and the lipid-A part of LPS. For example, KDO is replaced by 2-keto-D-glycero-D-talooctonic (KO) in Burkholderia cepacia, a Gram-negative bacterial pathogens that causes respiratory infection in cystic fibrosis patients [8].

\section{Conclusions}

This study is the first detailed biochemical composition analysis of an intermediately pathogenic Leptospira LPS, and the first to compare leptospiral LPS in Leptospira pathogen vs. intermediate species. Many sugars and fatty acid were found in L. interrogans Copenhageni L1-130 but not in the intermediately pathogenic L. licerasiae Varillal VAR010, which merits further investigation. Current and forthcoming comparative whole Leptospira genomic analysis will allow for detailed genetic/genomic, functional and structural analysis of leptospiral LPS, a molecule essential to diverse aspects of this spirochete's biology, which will improve our understand of mechanisms of pathogenesis and potential vaccine-related interventions.

\footnotetext{
Abbreviations

LPS: Lipopolysaccharides; GlcNAc: N-acetyl glucosamine; HexNAc: Nacetylhexoseamine; SDS-PAGE: Sodium dodecyl polyacrylamide gel electrophoresis; GC-MS: Gas chromatography-mass spectrometry; rfb: LPS biosynthetic locus; AAALAC: Association for Assessment and Accreditation of Laboratory Animal Care; EMJH: Ellinghausen-McCullough-Johnson-Harris medium; FAME: Fatty acid methyl ester (FAME); (Tri-Sil)-FAME: Trimethyl silyl ether; HOAc: Acetic acid; AQ layer: Aqueous layer; PH layer: Phenol layer; Ara: Arabinose (Ara); Rha: Rhamnose; Xyl: Xylose; Man: Mannose; Gal: Galactose; GalNAc: N-acetyl galactosamine; QuiNAc: N-acetyl quinovosamine; FucNAc: N-acetyl fucosamine; KDO: 2-keto-3-deoxymanno-octulosonic acid; KO: 2-keto-D-glycero-D-talo-octonic; TLR: Toll-like receptor.
}

Competing interests

The authors declare that they have no competing interests. 


\section{Authors' contributions}

Conceived and designed the experiments ( $\mathrm{V}, \mathrm{KP}$ and $\mathrm{BC}$ ), performed experiments $(B C, K P, S B$ and $K B)$ and analyzed the data and wrote the paper (KP, BC, MM and JV). All authors read and approved the final manuscript.

\section{Acknowledgments}

We thank Paula Maguina for her logistic support for this paper. We are thankful for the excellent support and facilities provided at Glycotechnology Core Resources, UCSD to complete the work. We also thank Timo Meerloo, Electron Microscopy Core Facility, Cellular and Molecular Medicine, UCSD for his contributions to this work.

\section{Author details}

'Division of Infectious Diseases, Department of Medicine, Biomedical Research Facility, University of California San Diego, 9500 Gilman Drive, BRF 2, Room 5220, La Jolla 92093-0760, California, USA. Glycotechnology Core Resources, University of California San Diego, 9500 Gilman Drive, BRF 2, Room 4243, La Jolla 92093-0687, California, USA.

Received: 16 May 2015 Accepted: 23 October 2015

Published online: 30 October 2015

\section{References}

1. Vinetz JM. Leptospirosis. Curr Opin Infect Dis. 2001;14(5):527-38.

2. Bharti AR, Nally JE, Ricaldi JN, Matthias MA, Diaz MM, Lovett MA, et al. Leptospirosis: A zoonotic disease of global importance. Lancet Infect Dis. 2003;3(12):757-71.

3. Ricaldi JN, Fouts DE, Selengut JD, Harkins DM, Patra KP, Moreno A, et al. Whole genome analysis of leptospira licerasiae provides insight into leptospiral evolution and pathogenicity. PLoS Negl Trop Dis 2012;6(10):e1853.

4. Bulach DM, Kalambaheti T, de la Pena-Moctezuma A, Adler B. Lipopolysaccharide biosynthesis in Leptospira. J Mol Microbiol Biotechnol. 2000;2(4):375-80.

5. Adler B, de la Pena MA. Leptospira and leptospirosis. Vet Microbiol. 2010;140(3-4):287-96.

6. Palaniappan RU, Ramanujam S, Chang YF. Leptospirosis: Pathogenesis, immunity, and diagnosis. Curr Opin Infect Dis. 2007;20(3):284-92.

7. Adler B. Vaccines against leptospirosis. Curr Top Microbiol Immunol. 2015:387:251-72.

8. Erridge $\mathrm{C}$, Bennett-Guerrero E, Poxton IR. Structure and function of lipopolysaccharides. Microbes and infection Institut Pasteur. 2002;4(8):837-51.

9. Darveau RP, Hancock RE. Procedure for isolation of bacterial lipopolysaccharides from both smooth and rough Pseudomonas aeruginosa and Salmonella typhimurium strains. J Bacteriol. 1983;155(2):831-8.

10. Cardoso PG, Macedo GC, Azevedo V, Oliveira SC. Brucella spp noncanonical LPS: Structure, biosynthesis, and interaction with host immune system. Microb Cell Fact. 2006;5:13.

11. Isogai E, Isogai H, Ito N. Decreased lipopolysaccharide content and enhanced susceptibility of leptospiras to serum leptospiricidal action and phagocytosis after treatment with diphenylamine. Zentralbl Bakteriol Mikrobiol Hyg A. 1986;262(4):438-47.

12. Murray GL, Srikram A, Henry R, Hartskeerl RA, Sermswan RW, Adler B. Mutations affecting Leptospira interrogans lipopolysaccharide attenuate virulence. Mol Microbiol. 2010;78(3):701-9.

13. Nally JE, Chow E, Fishbein MC, Blanco DR, Lovett MA. Changes in lipopolysaccharide $\mathrm{O}$ antigen distinguish acute versus chronic Leptospira interrogans infections. Infect Immun. 2005;73(6):3251-60.

14. Widiyanti D, Koizumi N, Fukui T, Muslich LT, Segawa T, Villanueva SY, et al. Development of immunochromatography-based methods for detection of leptospiral lipopolysaccharide antigen in urine. Clin Vaccine Immunol. 2013;20(5):683-90

15. Chapman AJ, Everard CO, Faine S, Adler B. Antigens recognized by the human immune response to severe leptospirosis in Barbados. Epidemiol Infect. 1991;107(1):143-55.

16. Matsuo K, Isogai E, Araki Y. Control of immunologically crossreactive leptospiral infection by administration of lipopolysaccharides from a nonpathogenic strain of Leptospira biflexa. Microbiol Immunol. 2000;44(11):887-90.

17. Wang Z, Jin L, Wegrzyn A. Leptospirosis vaccines. Microb Cell Fact. 2007;6:39.
18. Matthias MA, Ricaldi JN, Cespedes M, Diaz MM, Galloway RL, Saito M, et al. Human leptospirosis caused by a new, antigenically unique Leptospira associated with a Rattus species reservoir in the Peruvian Amazon. PLoS Negl Trop Dis. 2008;2(4):e213.

19. Coutinho ML, Matsunaga J, Wang LC, de la Pena MA, Lewis MS, Babbitt JT, et al. Kinetics of Leptospira interrogans infection in hamsters after intradermal and subcutaneous challenge. PLoS Negl Trop Dis. 2014;8(11):e3307.

20. Ko Al, Goarant C, Picardeau M. Leptospira: the dawn of the molecular genetics era for an emerging zoonotic pathogen. Nat Rev Microbiol. 2009; $7(10): 736-47$

21. Vinh T, Adler B, Faine S. Ultrastructure and chemical composition of lipopolysaccharide extracted from Leptospira interrogans serovar copenhageni. J Gen Microbiol. 1986;132(1):103-9.

22. de la Pena-Moctezuma A, Bulach DM, Kalambaheti T, Adler B. Comparative analysis of the LPS biosynthetic loci of the genetic subtypes of serovar Hardjo: Leptospira interrogans subtype Hardjoprajitno and Leptospira borgpetersenii subtype Hardjobovis. FEMS Microbiol Lett. 1999;177(2):319-26.

23. Nascimento AL, Ko Al, Martins EA, Monteiro-Vitorello CB, Ho PL, Haake DA, et al. Comparative genomics of two Leptospira interrogans serovars reveals novel insights into physiology and pathogenesis. J Bacteriol. 2004;186(7):2164-72.

24. Westphal O, Jann K. Bacterial lipopolysaccharides: extraction with phenolwater and future applications of the procedure., vol. 5. New York: Academic; 1965. New York.

25. Que-Gewirth NL, Ribeiro AA, Kalb SR, Cotter RJ, Bulach DM, Adler B, et al. A methylated phosphate group and four amide-linked acyl chains in leptospira interrogans lipid A. The membrane anchor of an unusual lipopolysaccharide that activates TLR2. J Biol Chem. 2004;279(24):25420-9.

26. Bulach DM, Kalambaheti T, de la Pena-Moctezuma A, Adler B. Lipopolysaccharide biosynthesis in Leptospira. J Mol Microbiol Biotechnol. 2000;2(4):375-80

27. Bulach DM, Kalambaheti T, de la Pena-Moctezuma A, Adler B. Functional analysis of genes in the rfb locus of Leptospira borgpetersenii serovar Hardjo subtype Hardjobovis. Infect Immun. 2000;68(7):3793-8.

28. Faine $S$, Adler B, Palit A. Chemical, serological and biological properties of a serotype-specific polysaccharide antigen in Leptospira. Aust J Exp Biol Med Sci. 1974;52(2):311-9.

29. Adler B, Faine S. Host immunological mechanisms in the resistance of mice to leptospiral infections. Infect Immun. 1977;17(1):67-72.

30. Adler B, Faine S. Serological cross-reactions of leptospiral lipopolysaccharide (F4) antigen. Zbl Bakt Hyg I Abt Orig. 1979;A244:291-301.

31. Adler B, Faine S. A pomona serogroup-specific, agglutinating antigen in leptospira, identified by monoclonal antibodies. Pathology. 1983;15:247-50.

32. Ballard SA, Adler B, Millar BD, Chappel RJ, Jones RT, Faine S, et al. The Immunoglobulin response of swine following experimental infection with leptospira interrrogans serovar pomona. Zentralblatt fur Bakteriologie Mikrobiologie und Hyg. 1984;A256:510-7.

33. Jost BH, Adler B, Vinh T, Faine S. A monoclonal antibody reacting with a determinant on leptospiral lipopolysaccharide protects guinea pigs against leptospirosis. J Med Microbiol. 1986;22:269-75.

34. Farrelly HE, Adler B, Faine S. Opsonic monoclonal antibodies against lipopolysaccharide antigens of Leptospira interrogans serovar hardjo. J Med Microbiol. 1987;23:1-7.

35. Jost BH, Adler B, Faine S. Reaction of monoclonal antibodies with species specific determinants in Leptospira interrogans outer envelope. J Med Microbiol. 1988;27:51-7.

36. Jost BH, Adler B, Faine S. Experimental immunisation of hamsters with lipopolysaccharide antigens of Leptospira interrogans. J Med Microbiol. 1989;29:115-20.

37. Marcsisin RA, Bartpho T, Bulach DM, Srikram A, Sermswan RW, Adler B, et al. Use of a high-throughput screen to identify Leptospira mutants unable to colonize the carrier host or cause disease in the acute model of infection. J Med Microbiol. 2013;62(Pt 10):1601-8.

38. Goris MG, Wagenaar JF, Hartskeerl RA, van Gorp EC, Schuller S, Monahan AM, et al. Potent innate immune response to pathogenic leptospira in human whole blood. PLoS One. 2011;6(3):e18279.

39. Wildschutte H, Wolfe DM, Tamewitz A, Lawrence JG. Protozoan predation, diversifying selection, and the evolution of antigenic diversity in Salmonella. Proc Natl Acad Sci U S A. 2004;101(29):10644-9. 
40. Wu LH, Tsai CM, Frasch CE. A method for purification of bacterial R-type lipopolysaccharides (lipooligosaccharides). Anal Biochem. 1987;160(2):281-9.

41. Wu SH, Jiang SX, Wang HQ, Nie DK, Zhu GF. Studies on endotoxin of Leptospira. V. The effect of EDTA-Na on the release of the LPS of Leptospira interrogans serovar lai. Wei Sheng Wu Xue Bao. 1989;29(5):390-3.

42. Knirel YA, Lindner B, Vinogradov EV, Kocharova NA, Senchenkova SN, Shaikhutdinova RZ, et al. Temperature-dependent variations and intraspecies diversity of the structure of the lipopolysaccharide of Yersinia pestis. Biochemistry. 2005:44(5):1731-43.

43. Rahmati-Bahram A, Magee JT, Jackson SK. Temperature-dependent aminoglycoside resistance in Stenotrophomonas (Xanthomonas) maltophilia; alterations in protein and lipopolysaccharide with growth temperature. J Antimicrob Chemother. 1996;37(4):665-76.

44. Kilcoyne M, Twomey ME, Gerlach JQ, Kane M, Moran AP, Joshi L. Campylobacter jejuni strain discrimination and temperature-dependent glycome expression profiling by lectin microarray. Carbohydr Res. 2014;389:123-33.

45. Wang Z, Vinogradov E, Li J, Lund V, Altman E. Structural characterization of the lipopolysaccharide O-antigen from atypical isolate of Vibrio anguillarum strain 1282. Carbohydr Res. 2009;344(11):1371-5.

46. Veremeichenko SN, Zdorovenko GM. [Structure and properties of the lipopolysaccharide of Pseudomonas fluorescens IMV 2366 (biovar III)]. Mikrobiologiia. 2004;73(3):312-9.

47. Vinh TU, Shi MH, Adler B, Faine S. Characterization and taxonomic significance of lipopolysaccharides of Leptospira interrogans serovar hardjo. J Gen Microbiol. 1989;135(10):2663-73.

48. Bahat-Samet E, Castro-Sowinski S, Okon Y. Arabinose content of extracellular polysaccharide plays a role in cell aggregation of Azospirillum brasilense. FEMS Microbiol Lett. 2004;237(2):195-203.

49. Burdman S, Jurkevitch E, Soria-Diaz ME, Serrano AM, Okon Y. Extracellular polysaccharide composition of Azospirillum brasilense and its relation with cell aggregation. FEMS Microbiol Lett. 2000;189(2):259-64.

50. Nahori MA, Fournie-Amazouz E, Que-Gewirth NS, Balloy V, Chignard M Raetz CR, et al. Differential TLR recognition of leptospiral lipid $A$ and lipopolysaccharide in murine and human cells. J Immunol. 2005;175(9):6022-31.

51. Steeghs L, den Hartog R, den Boer A, Zomer B, Roholl P, van der Ley P. Meningitis bacterium is viable without endotoxin. Nature. 1998;392(6675):449-50.

52. Wang J, Ma W, Wang Z, Li Y, Wang X. Construction and characterization of an Escherichia coli mutant producing Kdo(2)-lipid A. Mar Drugs. 2014;12(3):1495-511.

53. Rietschel ET, Brade H, Holst O, Brade L, Muller-Loennies S, Mamat U, et al. Bacterial endotoxin: Chemical constitution, biological recognition, host response, and immunological detoxification. Curr Top Microbiol Immunol. 1996;216:39-81.

54. Rassek M, Paar G, Schultheis KH, Simons C, Kohle K. [Function of the hospital round within the scope of internal-psychosomatic patient care]. Verh Dtsch Ges Inn Med. 1975;81:1735-7.

55. Szponar B, Norin E, Midtvedt T, Larsson L. Limitations in the use of 3 hydroxy fatty acid analysis to determine endotoxin in mammalian samples. J Microbiol Methods. 2002;50(3):283-9.

56. Pomorska D, Larsson L, Skorska C, Sitkowska J, Dutkiewicz J. Levels of bacterial endotoxin in air of animal houses determined with the use of gas chromatography-mass spectrometry and Limulus test. Ann Agric Environ Med. 2007;14(2):291-8.

57. Faine S. Iron as a growth requirement for pathogenic Leptospira. J Gen Microbiol. 1959;20(2):246-51.

58. Zuerner RL: Laboratory maintenance of pathogenic Leptospira. Curr Protoc Microbiol 2005, Chapter 12:Unit 12E 11 doi: 10.1002/ 9780471729259.mc12e01s00.

59. de Faria MT, Calderwood MS, Athanazio DA, McBride AJ, Hartskeerl RA Pereira MM, et al. Carriage of Leptospira interrogans among domestic rats from an urban setting highly endemic for leptospirosis in Brazil. Acta Trop. 2008;108(1):1-5.

60. Baseman JB, Cox CD. Intermediate energy metabolism of Leptospira. J Bacteriol. 1969;97(3):992-1000.

61. Burth P, Younes-Ibrahim M, Santos MC, Castro-Faria Neto HC, de Castro Faria MV. Role of nonesterified unsaturated fatty acids in the pathophysiological processes of leptospiral infection. J Infect Dis. 2005:191(1):51-7.

\section{Submit your next manuscript to BioMed Central and take full advantage of:}

- Convenient online submission

- Thorough peer review

- No space constraints or color figure charges

- Immediate publication on acceptance

- Inclusion in PubMed, CAS, Scopus and Google Scholar

- Research which is freely available for redistribution 